\title{
Vida longa e próspera
}

\section{Long life and prosperity}

\section{Vida larga y prosperidad}

Maria Cristina Soares Guimarães | cristina.guimaraes@icict.fiocruz.br

Fundação Oswaldo Cruz, Instituto de Comunicação e Informação Científica e Tecnológica, Laboratório de Informação Científica e Tecnológica em Saúde. Rio de Janeiro, Brasil.

Palavras-chave: acesso livre; Reciis; sustentabilidade; década; periódicos científicos.

Keywords: open access; Reciis; sustainability; decade; scientific journals.

Palabras clave: acceso abierto; Reciis; sustentabilidad; decenio; revistas periódicas.

Há dez anos a Revista Eletrônica de Comunicação, Informação \& Inovação em Saúde - Reciis foi lançada com a meta de ser "[...] um espaço acadêmico virtual de debates, reflexões, conexões e interconexões de ideias entre profissionais oriundos de instituições diversas e singulares" ${ }^{\text {. O que }}$ não foi dito à época é que a Reciis seria o primeiro periódico da Fundação Oswaldo Cruz - Fiocruz - totalmente inserido no Movimento do Acesso Livre (Budapest Open Access Initiative, 2002) ${ }^{2}$, e que se juntou a um conjunto de inovações que o Instituto de Comunicação e Informação Científica e Tecnológica em Saúde - Icict - ousou protagonizar nos idos de 2007, culminando com o lançamento do Programa de Pós-Graduação em Informação e Comunicação em Saúde - PPGICS/ Icict/Fiocruz, em 2009. Ambas as iniciativas seguiram seus caminhos, não necessariamente convergentes, em respeito às suas missões e compromissos com a agenda científica. Entretanto, a Reciis também se colocou como importante fonte de informação para os iniciantes desbravadores 
da interdisciplinaridade fundante de ambas as iniciativas: o encontro entre a comunicação, a informação, a ciência, tecnologia e inovação (C,T\&I) e a saúde.

Os desafios de sobrevivência dos periódicos científicos no contexto da ciência brasileira são inúmeros, e vão desde os custos de infraestrutura e manutenção até o potencial para atrair bons textos, especialmente à luz da política, por vezes predatória, do indicador Qualis imposta pela Coordenação de Aperfeiçoamento de Pessoal de Nível Superior - Capes, o que faz com que periódicos novos sejam pouco sedutores. Assim, comemorar uma década, mantendo a periodicidade, sendo indexada em bases de dados secundárias e, mais importante, galgando níveis consideráveis no indicador Qualis é, por si só, um feito excepcional ${ }^{3}$.

De fato, a análise de Bochner, Murtinho, Barcellos, Reis, Santa Rita ${ }^{3}$ é um testemunho fidedigno dessa trajetória sustentável, e os números ali registrados contam uma história de autores e temas comprometidos e vocacionados para a interdisciplinaridade, e que expressam a relevância dos mesmos para o campo da saúde. Os números talvez não deem conta de um conjunto de anônimos, especialmente nosso corpo de pareceristas, que imprimiram a qualidade de que muito nos orgulhamos.

A todos, aplausos pelo compromisso e pelo profissionalismo.

Vida longa e próspera à Reciis.

\section{Referências}

1. Machado CJS. A arena da saúde na dinâmica do tempo presente. R EletrComun, InfInov Saúde [Internet]. 2007 jan-jun [acesso em 2017 maio4];1(1):5-7. Disponível em: https://www.reciis.icict. fiocruz.br/index.php/reciis/article/view/874.

2. Budapest Open Access Initiative [Internet]. [placeunknow]; 2002 [cited 2017 May 03]. Disponível em: http://www.budapestopenaccessinitiative.org

3. Bochner R, Murtinho R, Barcellos C, Reis JG, Santa Rita T. Métricas contam a história e a trajetória da Revista Eletrônica de Comunicação, Informaç̧ão e Inovação em Saúde - Reciis [Internet]. Anais; 2014 out. 27-31; Belo Horizonte. Belo Horizonte: UFMG, ECI; 2014 [citado em 2017 maio 04]. Disponível em: http://enancib2014.eci.ufmg.br/documentos/anais/anais-gt11. 